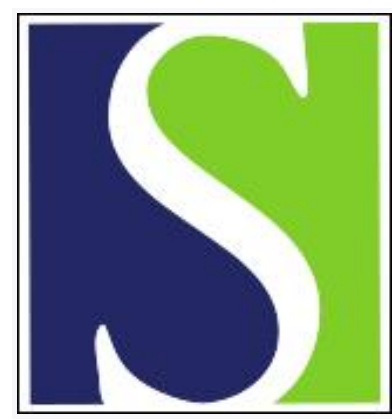

Scand J Work Environ Health 2008;34(1):48-54

https://doi.org/10.5271/sjweh.1163

Issue date: 29 Feb 2008

Job strain and arteriosclerosis in three different types of arteries among male Japanese factory workers

by Michikawa T, Nishiwaki Y, Nomiyama T, Uemura T, O'Uchi T, Sakurai H, Omae K, Takebayashi T

Affiliation: Department of Preventive Medicine and Public Health, School of Medicine, Keio University, 35 Shinanomachi, Shinjuku-ku, Tokyo 160-8582, Japan.

Refers to the following texts of the Journal: 2006;32(6):431-442 2004;30(2):85-128 2005;31(5):352-359 2006;32(6):413-419

Key terms: aorta; arteriosclerosis; brain magnetic resonance imaging; carotid artery; cerebral artery; cross-sectional study; factory worker; Japan; job content questionnaire; job strain; magnetic resonance imaging; man; MRI

This article in PubMed: www.ncbi.nlm.nih.gov/pubmed/18427698 


\title{
Job strain and arteriosclerosis in three different types of arteries among male Japanese factory workers
}

\author{
by Takehiro Michikawa, MD, ${ }^{1}$ Yuji Nishiwaki, MD, ${ }^{1}$ Tetsuo Nomiyama, MD, ${ }^{2}$ Takamoto Uemura, MD, ${ }^{3}$ \\ Toshihiro O'Uchi, MD, ${ }^{4}$ Haruhiko Sakurai, MD, ${ }^{5}$ Kazuyuki Omae, MD, ${ }^{1}$ Toru Takebayashi, MD'
}

\begin{abstract}
Michikawa T, Nishiwaki Y, Nomiyama T, Uemura T, O'Uchi T, Sakurai H, Omae K, Takebayashi T. Job strain and arteriosclerosis in three different types of arteries among male Japanese factory workers. Scand J Work Environment \& Health. 2008;34(1):48-54.
\end{abstract}

\begin{abstract}
Objectives This study evaluated the association between job strain and subclinical indicators of arteriosclerosis simultaneously in the cerebral artery, the aorta, and the carotid artery.

Methods The participants in this cross-sectional study consisted of 352 male factory workers between the ages of 24.9 to 55.8 (mean 41.7) years who had not been exposed to any hazardous chemicals in Japan. Job strain was measured using a Japanese version of the Job Content Questionnaire developed by Karasek. The following subclinical indicators of arteriosclerosis were examined by noninvasive procedures: hyperintense spots in T2weighted images in brain magnetic resonance imaging (MRI), pulse wave velocity of the aorta, and the stiffness parameter of the carotid artery using ultrasound and systolic and diastolic blood pressure.

Results After control for potential confounders, high job strain was associated with an increased prevalence of hyperintense spots (adjusted odds ratio 2.53, 95\% confidence interval 1.14-5.63), and elevated pulse-wave velocity (adjusted increase in percent 3.5, 95\% confidence interval 0.0-6.9). The stiffness parameter tended to be elevated in the high job-strain group although this trend was not statistically significant. Job strain showed no relation to blood pressure.

Conclusions In this study, job strain was associated with subclinical indicators of arteriosclerosis in different arteries although the association was not statistically significant for the carotid artery. New information is offered by brain MRI for arteriosclerosis in the cerebral artery. An increase in hyperintense spots may explain the link between job strain and cerebrovascular disease.
\end{abstract}

Key terms aorta; brain magnetic resonance imaging; carotid artery; cerebral artery; cross-sectional study; Job Content Questionnaire.

Work stress plays an important part in illness. It is particularly known as a risk factor for cardiovascular disease (1-6), hypertension (7-9), and arteriosclerosis (10-12). In research on the health effects of work stress, the demand-control model is well known, and Karasek et al $(13,14)$ reported that high job strain, defined as a combination of high job demands and low job control, was related to an increased incidence of cardiovascular disease in populations in Sweden and the United States. Most researchers have chosen ischemic heart disease as the outcome of their studies, while there have only been a few studies in which cerebrovascular disease was set as the end point $(5,15,16)$. It is necessary to evaluate the relationship between job strain and cerebrovascular disease because cerebrovascular disease is a very important illness, constituting the third leading cause of death in Japan (17).

Although it has been hypothesized that high job strain causes cardiovascular disease and cerebrovascular disease through the progression of arteriosclerosis

1 Department of Preventive Medicine and Public Health, School of Medicine, Keio University, Tokyo, Japan.

2 Department of Preventive Medicine and Public Health, School of Medicine, Shinshu University, Nagano, Japan.

3 Department of Preventive Medicine and Public Health, School of Medicine, Kyorin University, Tokyo, Japan

4 Kameda General Hospital, Chiba, Japan.

5 Occupational Health Research and Development Center, Japan Industrial Safely and Health Association, Tokyo, Japan.

Reprint requests to: Dr T Takebayashi, Department of Preventive Medicine and Public Health, School of Medicine, Keio University, 35 Shinanomachi, Shinjuku-ku, Tokyo 160-8582, Japan. [E-mail: ttake@sc.itc.keio.ac.jp] 
$(6,18)$, the underlying mechanism is still unclear. Recent advances in medical technology have made it possible to evaluate the subclinical conditions of arteriosclerosis without invasive procedures. The aim of the study was to use these technologies to investigate the relation between job strain and subclinical indicators of arteriosclerosis simultaneously in three different types of arteries, including the cerebral artery, the aorta, and the carotid artery.

\section{Study population and methods}

\section{Study population}

Our study is part of an occupational cohort study in which the effects of carbon disulfide exposure on arteriosclerosis were examined among Japanese factory workers. Briefly, the participants were 432 male workers exposed to carbon disulfide and 402 male reference workers from the same factories who had not been exposed to any hazardous chemicals, including carbon disulfide. Those with any history of chronic disease such as hypertension, diabetes mellitus, stroke, and cardiovascular disease were excluded from the study at baseline. Details of the study and the results of the cohort study have been described elsewhere $(19,20)$. To investigate the effects of job strain on arteriosclerosis, we added a questionnaire in the follow-up survey of 1998-1999. Thus this report concerns a cross-sectional observation in which the participants were limited to those who had not been exposed to hazardous chemicals and had answered the questionnaire. Namely, the 352 male factory workers who participated in the follow-up survey as the reference group were included.

\section{Assessment of job strain}

Job strain was evaluated by the Japanese version of the Job Content Questionnaire (JCQ) developed by Karasek (21), addressing job demands, job control, and social support $(22,23)$. In this study, the interaction between job demands and job control was defined as job strain, and job strain was determined in two ways. First, we calculated the ratio of the score for crude job demands to the score for crude job control. Then, the participants at the median value or higher were classified as having high job strain (8). Second, the high job-strain (dichotomy) group was defined as having both a score above the median for job demands and below the median for job control (8). Each score for job demand, job control, and social support was dichotomized at the median value by two groups (high and low).

\section{Subclinical indicators of arteriosclerosis}

Arteriosclerosis was evaluated for three different types of arteries, including the cerebral artery, the aorta, and the carotid artery.

To evaluate arteriosclerosis in the cerebral artery, we used brain magnetic resonance inaging (MRI). The brain MRI was performed in a hospital near each factory, using MRI equipment with a magnetic density of at least $0.5 \mathrm{~T}$. We used the following parameters with T2-weighted images at transverse slices: TR/TE 2000/100, matrix size of $256 \times 256$, field of view $25 \mathrm{~cm}$ with a thickness of $10 \mathrm{~mm}$ and a slice gap of $2 \mathrm{~mm}$. To equalize the quality of the films, the neuroradiologist offered some suggestions to the technicians for the first few participants. One trained neuroradiologist read all of the MRI films and measured the number of hyperintense spots in T2-weighted images in the cerebrum under a blinded condition. The diagnostic criteria for hyperintense spots were those recommended by the Japanese study subgroup on diagnostic criteria, pathogenesis, and management for asymptomatic cerebrovascular diseases (24). However, recent experiences have indicated that hyperintense spots in brain MRI not only include cerebral infarction, but also myelin pallor and dilated perivascular spaces due to arteriosclerotic changes ( 25 , 26). Thus we used the expression hyperintense spots instead of "silent cerebral infarction" in our study. We divided the participants into the categories "none", "a few", "about 10", and "a lot" according to hyperintense spots rather than counting its numbers. Since no clear cut-off point has been proposed so far for the number of hyperintense spots in brain MRI representing clinical significance, we arbitrarily determined that the upper two classes of the four, "about 10" and "a lot" groups, would be considered to be positive for hyperintense spots. The clinical significance of this cut-off value should be examined by following up a cohort of MRI examinees in a future study.

The pulse-wave velocity (PWV) of the aorta was measured by the PWV-200 (Fukuda Electric Co, Tokyo, Japan), followed by adjustment for diastolic blood pressure. This value reflected the stiffness of the aortic wall and was strongly related to arteriosclerosis (27). The stiffness parameter of the carotid artery was examined by ultrasound (QRF-2000XA, Hayashi Electric Co, Tokyo, Japan), with control for diastolic blood pressure. This parameter was shown in association with arteriosclerosis $(28,29)$. To minimize both the inter- and intraobserver errors for the measurements of pulse-wave velocity and the stiffness parameter, we prepared the measurement protocol in which the measuring procedure was described in a step-by-step manner, and two parameters were measured by one trained clinical laboratory technologist. In addition, the examiner was adequately 
trained before starting the study and was asked to adhere to the standardized procedures. All three examinations were performed with the participants in the supine position. During the examinations, some factors with the possibility of influencing measurements such as last exercise, last shift, intake of caffeine, nicotine, and meals were not considered as we assumed that they may occur randomly.

Systolic and diastolic blood pressure were also examined as subclinical indicators of arteriosclerosis. They were measured with a sphygmomanometer by one research physician after at least 15 minutes of rest in an air-conditioned room.

\section{Covariates}

Information on possible risk factors for arteriosclerosis was also collected. Age, height, weight (later, the body mass index was calculated), educational history, and shift work (30) were obtained from company records. Data on smoking status, alcohol consumption, and presence of type-A behavior patterns were collected through a self-administered questionnaire. Specifically, pack-years was calculated as the index of smoking status, and grams of ethanol per day was calculated as an index of alcohol consumption. Type-A behavior pattern was assessed according to the questionnaire by Maeda (31), with a total score of 17 or greater indicating type-A behavior. The clinical laboratory items included in the study were total cholesterol, low-density lipoprotein,

Table 1. Characteristics of the study population. $(S D=$ standard deviation)

\begin{tabular}{|c|c|c|c|c|}
\hline Characteristic & $\mathrm{N}$ & Mean & SD & $\begin{array}{c}\text { Prevalence } \\
(\%)\end{array}$ \\
\hline Age (years) & 352 & 41.7 & 9.1 & $\cdot$ \\
\hline Smoking status & & & & $\cdot$ \\
\hline None & 112 & . & . & 32.5 \\
\hline$<20$ pack-years & 96 & . & . & 27.8 \\
\hline$\geq 20$ pack-years & 137 & $\cdot$ & $\cdot$ & 39.7 \\
\hline \multicolumn{5}{|l|}{ Alcohol consumption } \\
\hline None & 110 & $\cdot$ & $\cdot$ & 31.9 \\
\hline$<30 \mathrm{~g}$ ethanol/day & 123 & . & . & 35.6 \\
\hline$\geq 30 \mathrm{~g}$ ethanol/day & 112 & $\cdot$ & $\cdot$ & 32.5 \\
\hline Type A behavior pattern & 346 & $\cdot$ & $\cdot$ & 28.0 \\
\hline Body mass index $\left(\mathrm{kg} / \mathrm{m}^{2}\right)$ & 350 & 23.1 & 2.9 & . \\
\hline Education ${ }^{\text {a }}$ & 352 & $\cdot$ & $\cdot$ & 71.3 \\
\hline Shift work & 352 & $\cdot$ & $\cdot$ & 88.6 \\
\hline \multicolumn{5}{|c|}{ Job Content Questionnaire (scores) } \\
\hline Job demands ${ }^{b}$ & 341 & 30.6 & 1.2 & $\cdot$ \\
\hline Job control ${ }^{b}$ & 339 & 60.1 & 1.2 & $\cdot$ \\
\hline Social support ${ }^{b}$ & 333 & 22.3 & 1.2 & . \\
\hline
\end{tabular}

high-density lipoprotein, and hemoglobin $\mathrm{A}_{1 \mathrm{c}}\left(\mathrm{HbA}_{1 \mathrm{c}}\right)$. All of these samples were analyzed by a nationwide clinical laboratory that runs an internal quality control program every day and participates in external quality control programs.

\section{Statistical analysis}

The values for the pulse-wave velocity, the stiffness parameter, and systolic and diastolic blood pressure were transformed to common logarithms because the distribution was skewed to the right. Comparison of the prevalence or the geometric means of the subclinical indicators of arteriosclerosis according to the job strain categories (job demand, job control, social support, job strain) was carried out with the $\chi^{2}$ test or Student's t-test. There was no interaction between the job strain variables and each covariate. To control for possible confounders, a logistic regression model for hyperintense spots was developed, and an odds ratio was calculated. With multiple regression models for pulse-wave velocity and the stiffness parameter, regression coefficients were calculated, followed by exponential transformation. The percentage of the increases in pulse-wave velocity and the stiffness parameter was then determined. The initial step only included age (continuous variable) when we constructed an adjusted model. Then the multivariateadjusted model was constructed by adding smoking status (none, $<20, \geq 20$ pack-years), alcohol consumption (none, $<30, \geq 30 \mathrm{~g}$ ethanol/day), total cholesterol, systolic blood pressure, $\mathrm{HbA}_{1 \mathrm{c}}$, presence of a type-A behavior pattern (yes, no), body mass index, educational history (junior high school, senior high school or higher), and shift work (yes, no) as covariates. Certainly, the multivariate-adjusted model for blood pressure excluded systolic blood pressure. Logistic and multiple regression models were calculated with the low-strain group, with the exception of high job control and social support, as a reference.

The analysis was done using the SPSS package for Windows, version 14.0 (SPSS Inc, Chicago, IL, USA).

\section{Results}

The characteristics of the study population are shown in table 1. Two-thirds were smokers. The proportion of light or moderate ( $<30 \mathrm{~g}$ ethanol/day) and heavy ( $\geq 30 \mathrm{~g}$ ethanol/day) drinkers was $35.6 \%$ and $32.5 \%$, respectively.

Table 2 shows the association between the job-strain categories and hyperintense spots. The crude prevalence of hyperintense spots in T2-weighted images was 
higher for the high job-strain (ratio) group than for the low-strain group ( $\mathrm{P}=0.047$ by the $\chi^{2}$ test). This relation remained statistically significant even after control for potential confounders in the multivariate-adjusted model [adjusted odds ratio (aOR) 2.53, 95\% confidence interval (95\% CI) 1.14-5.63].

Table 3 shows the association between the job-strain categories and the pulse-wave velocity and the stiffness parameter. The crude geometric means of the pulse-wave velocity and the stiffness parameter tended to be slightly higher in the high job-strain groups than in the low jobstrain groups, except for social support with respect to the stiffness parameter, although this trend was not statistically significant. A multivariate analysis controlling for potential confounders revealed that the pulse-wave velocity was increased for the high job-demand and high job-strain (both ratio and dichotomy) groups. The adjusted increase in the pulse-wave velocity was $3.5 \%$ (95\% CI 0.7-6.4\%) for high job demand, $2.6 \%$ (95\% CI $-0.2-5.7 \%$ ) for high job strain (ratio; this was of marginal significance), and 3.5\% (95\% CI $0.0-6.9 \%$ ) for high job strain (dichotomy). With regard to the stiffness parameter, an almost 3\% increase was observed in the multivariate-adjusted models for high job demand and high job strain (both ratio and dichotomy). However, it did not reach statistical significance.

The crude geometric means for blood pressure in the high job-strain group tended to be higher than that in the low job-strain group. When the adjusted model was applied, job strain showed no relation to blood pressure (data not shown).

\section{Discussion}

This cross-sectional study showed that job strain was associated with arteriosclerosis in different types of arteries. In particular, high job strain doubled the odds for hyperintense spots in brain MRI. Our reports could support the hypothesis that high job strain causes cardiovascular disease and cerebrovascular disease through the progression of arteriosclerosis. The advantage of our study was to evaluate the subclinical indicators of arteriosclerosis simultaneously in three different types of arteries by noninvasive methods.

Many studies have shed light on the relationship between high job strain and an elevated risk of cardiovascular disease $(6,18)$. In addition, a few studies have reported an association between job strain and cerebrovascular disease. Uchiyama et al (5) followed 1615 male and female Japanese workers aged 40-65 years who had been treated for hypertension. They evaluated the relation between job strain and cardiovascular events defined as initial cerebral hemorrhage, cerebral infarction,
Table 2. Association between the job-strain categories and hyperintense spots. $(\mathrm{OR}=$ odds ratio, $95 \% \mathrm{Cl}=95 \%$ confidence interval)

\begin{tabular}{|c|c|c|c|c|c|c|}
\hline \multirow{2}{*}{$\begin{array}{l}\text { Job strain } \\
\text { category }\end{array}$} & \multicolumn{6}{|c|}{ Hyperintense spots ${ }^{a}$} \\
\hline & $\mathrm{N}$ & $\begin{array}{c}\text { Prevalence } \\
(\%)\end{array}$ & $\begin{array}{l}\text { Age- } \\
\text { adjusted } \\
\mathrm{OR}^{\mathrm{b}}\end{array}$ & $95 \% \mathrm{Cl}$ ○ & $\begin{array}{c}\text { Multivariate } \\
\text { adjusted } \\
\mathrm{OR}^{\mathrm{d}}\end{array}$ & \\
\hline \multicolumn{7}{|c|}{ Job demand } \\
\hline $\begin{array}{l}\text { Low } \\
\text { High }\end{array}$ & $\begin{array}{l}160 \\
171\end{array}$ & $\begin{array}{l}11.3 \\
14.0\end{array}$ & $\begin{array}{l}1.00 \\
1.62\end{array}$ & $\begin{array}{c}\cdot \\
0.81-3.25\end{array}$ & $\begin{array}{l}1.00 \\
1.72\end{array}$ & 0.80-3.69 \\
\hline \multicolumn{7}{|c|}{ Job control } \\
\hline $\begin{array}{l}\text { High } \\
\text { Low }\end{array}$ & $\begin{array}{l}179 \\
151\end{array}$ & $\begin{array}{r}9.5 \\
15.9\end{array}$ & $\begin{array}{l}1.00 \\
1.48\end{array}$ & $\stackrel{\cdot}{0.74-2.97}$ & $\begin{array}{l}1.00 \\
1.58\end{array}$ & $0.71-3.53$ \\
\hline \multicolumn{7}{|c|}{ Social support } \\
\hline $\begin{array}{l}\text { High } \\
\text { Low }\end{array}$ & $\begin{array}{l}199 \\
125\end{array}$ & $\begin{array}{l}11.1 \\
14.2\end{array}$ & $\begin{array}{l}1.00 \\
1.31\end{array}$ & $\stackrel{\cdot}{0.65-2.64}$ & $\begin{array}{l}1.00 \\
1.29\end{array}$ & 0.61-2.71 \\
\hline \multicolumn{7}{|c|}{ Job strain (ratio) } \\
\hline $\begin{array}{l}\text { Low } \\
\text { High }\end{array}$ & $\begin{array}{l}168 \\
161\end{array}$ & $\begin{array}{c}8.9 \\
16.1^{\dagger}\end{array}$ & $\begin{array}{l}1.00 \\
1.98\end{array}$ & $\underset{0.97-4.01}{\cdot}$ & $\begin{array}{l}1.00 \\
2.53\end{array}$ & $\underset{1.14-5.63}{\cdot}$ \\
\hline \multicolumn{7}{|c|}{ Job strain (dichotomy) } \\
\hline $\begin{array}{l}\text { Low } \\
\text { High }\end{array}$ & $\begin{array}{r}267 \\
62\end{array}$ & $\begin{array}{l}10.8 \\
17.7\end{array}$ & $\begin{array}{l}1.00 \\
1.80\end{array}$ & $\stackrel{\cdot}{0.85-3.77}$ & $\begin{array}{l}1.00 \\
1.97\end{array}$ & 0.88-4.39 \\
\hline
\end{tabular}

a The cut off for the number of hyperintense spots was set at "about 10".

${ }^{b}$ The job-strain categories and age were included in the logistic regression model.

c For the age-adjusted model.

${ }^{\mathrm{d}}$ Adding to variables in the age-adjusted model, smoking status (none, $<20$, $\geq 20$ pack-years), alcohol consumption (none, $<30, \geq 30 \mathrm{~g}$ ethanol/day), total cholesterol, systolic blood pressure, hemoglabin $A_{1}$, presence of type-A behavior pattern (yes, no), body mass index, educational history (junior high school, senior high school or higher), and shift work (yes, no) were included.

${ }^{\text {e }}$ For the multivariate-adjusted model.

${ }^{\dagger} \mathrm{P}=0.047$ according to the $\chi^{2}$ test.

subarachnoidal hemorrhage, myocardial infarction, heart failure, aortic aneurysm rupture, or sudden death. They showed an elevated risk of cardiovascular diseases in the active job-strain group (high job demands and high job control) [relative risk (RR) 2.89, 95\% CI 1.33-6.28) and in the high job-strain group (RR 2.45, 95\% CI 0.87-6.93). Kivimäki et al (16) followed 812 factory workers in Finland for 25 years and found an elevated hazard ratio (HR) for cardiovascular disease, including cerebrovascular disease, in the high job-strain group [adjusted hazard ratio (aHR) 2.22, 95\% CI 1.04-4.73]. In these two studies, however, cerebrovascular disease was not evaluated as an end point separate from other cardiovascular events, such as heart disease. Kuper et al (15) reported a borderline significant increase in the risk for ischemic stroke among Swedish women who had high job strain (HR 1.6, 95\% CI 0.9-3.0). Although an increased risk of cerebrovascular disease was observed in relation to high job strain, the pathways through the progression of arteriosclerosis remained unclear because of the difficulty of evaluating subclinical arteriosclerosis in the cerebral artery by noninvasive methods. MRI has now made this possible. To our knowledge, this is the 
Table 3. Association between the job strain categories and pulse-wave velocity and the stiffness parameter. (GM = geometric mean, GSD = geometric standard deviation, $95 \% \mathrm{Cl}=95 \%$ confidence interval)

\begin{tabular}{|c|c|c|c|c|c|c|c|c|c|c|}
\hline \multirow{3}{*}{$\begin{array}{l}\text { Job strain } \\
\text { category }\end{array}$} & \multicolumn{5}{|c|}{ Pulse-wave velocity } & \multicolumn{5}{|c|}{ Stiffness parameter } \\
\hline & \multirow[t]{2}{*}{ N } & \multirow[t]{2}{*}{ GM } & \multirow[t]{2}{*}{ GSD } & $\begin{array}{l}\text { Age- } \\
\text { adjusted } \\
\text { increase }^{a, b}\end{array}$ & $\begin{array}{l}\text { Multivariate- } \\
\text { adjusted } \\
\text { increase }^{\text {a, c }}\end{array}$ & \multirow[t]{2}{*}{$\mathrm{N}$} & \multirow[t]{2}{*}{ GM } & \multirow[t]{2}{*}{ GSD } & $\begin{array}{l}\text { Age- } \\
\text { adjusted } \\
\text { increase }^{\mathrm{a}, \mathrm{b}}\end{array}$ & $\begin{array}{l}\text { Multivariate } \\
\text { adjusted } \\
\text { increase }{ }^{\mathrm{a}, \mathrm{c}}\end{array}$ \\
\hline & & & & $\% \quad 95 \% \mathrm{Cl}$ & $\% \quad 95 \% \mathrm{Cl}$ & & & & $95 \% \mathrm{Cl}$ & $95 \% \mathrm{Cl}$ \\
\hline \multicolumn{11}{|c|}{ Job demand } \\
\hline Low & 157 & 6.62 & 1.14 & Reference & Reference & 159 & 6.94 & 1.34 & \multirow{2}{*}{$\begin{array}{l}\text { Reference } \\
3.8-2.6-10.2\end{array}$} & Reference \\
\hline High & 169 & 6.82 & 1.15 & $3.5 \quad 0.5-6.4$ & $3.5 \quad 0.7-6.4$ & 159 & 7.14 & 1.36 & & $3.0-3.3-9.6$ \\
\hline \multicolumn{11}{|l|}{ Job control } \\
\hline High & 178 & 6.73 & 1.14 & \multirow{2}{*}{$\begin{array}{l}\text { Reference } \\
-1.0-3.8-2.1\end{array}$} & \multirow{2}{*}{$\begin{array}{l}\text { Reference } \\
-0.2-3.3-2.6\end{array}$} & 171 & 6.95 & 1.28 & \multirow{3}{*}{$\begin{array}{l}\text { Reference } \\
-0.2-6.7-5.9\end{array}$} & \multirow{2}{*}{$\begin{array}{l}\text { Reference } \\
0.7-5.9-7.2\end{array}$} \\
\hline Low & 146 & 6.73 & 1.15 & & & 145 & 7.11 & 1.35 & & \\
\hline \multicolumn{10}{|c|}{ Social support } & \\
\hline High & 191 & 6.68 & 1.15 & \multirow{3}{*}{$\begin{array}{l}\text { Reference } \\
1.4-1.4-4.5\end{array}$} & \multirow{2}{*}{$\begin{array}{l}\text { Reference } \\
1.4-1.6-4.5\end{array}$} & 188 & 7.08 & 1.35 & \multirow{3}{*}{$\begin{array}{l}\text { Reference } \\
-4.5-11.4-2.1\end{array}$} & \multirow{2}{*}{$\begin{array}{l}\text { Reference } \\
-4.2-11.2-2.3\end{array}$} \\
\hline Low & 126 & 6.77 & 1.15 & & & 122 & 6.89 & 1.35 & & \\
\hline \multicolumn{9}{|c|}{ Job strain (ratio) } & & \\
\hline Low & 167 & 6.65 & 1.15 & \multirow{3}{*}{$\begin{array}{l}\text { Reference } \\
1.6-1.2-4.7\end{array}$} & \multirow{2}{*}{$\begin{array}{l}\text { Reference } \\
2.6-0.2-5.7\end{array}$} & 164 & 6.91 & 1.34 & Reference & Reference \\
\hline High & 156 & 6.79 & 1.15 & & & 151 & 7.15 & 1.35 & $2.8-3.3-9.1$ & $2.6-3.8-9.1$ \\
\hline \multicolumn{10}{|c|}{ Job strain (dichotomy) } & \\
\hline Low & 246 & 6.68 & 1.14 & \multirow{2}{*}{$\begin{array}{l}\text { Reference } \\
2.8-0.5-6.4\end{array}$} & Reference & 241 & 6.95 & 1.34 & Reference & Reference \\
\hline High & 77 & 6.89 & 1.16 & & $3.5 \quad 0.0-6.9$ & 74 & 7.28 & 1.34 & $3.5-3.8-11.2$ & $3.3-4.2-10.9$ \\
\hline
\end{tabular}

a With the multiple regression analysis, the regression coefficients were calculated and exponential transformation was performed. The percentage of the increases in the pulse-wave velocity and the stiffness parameter were then determined.

b The job strain categories and age were included in the multiple regression model.

${ }^{c}$ Adding to the variables in the age-adjusted model, smoking status (none, $<20, \geq 20$ pack-years), alcohol consumption (none, $<30, \geq 30 \mathrm{~g}$ ethanol/day), total cholesterol, systolic blood pressure, hemoglabin $A_{1 c}$, presence of type-A behavior pattern (yes, no), body mass index, educational history (junior high school, senior high school or higher) and shift work (yes, no) were included.

first epidemiologic study to assess the relation between job strain and subclinical findings in brain MRI.

Recent studies have revealed that hyperintense spots in $\mathrm{T} 2$-weighted images are predictive of future stroke $(32,33)$. Kobayashi et al (32) followed 933 persons $30-81$ years of age and found that hyperintense spots were a significant risk factor for stroke onset (multivariate OR 10.48, 95\% CI 3.63-30.21). In the United States, 3660 participants who underwent cranial MRI were followed for 4 years, and the incidence of stroke was much higher for the participants with hyperintense spots than for those without such spots (aHR 1.52, 95\% CI 1.10-2.10) (33). Therefore, our results could support the hypothesis that high job strain causes cerebrovascular disease through the progression of arteriosclerosis.

The association between high job strain and the elevated pulse-wave velocity observed in our study was consistent with the findings of other studies (18). In contrast, a negative association between job strain and brachial-ankle pulse-wave velocity among male Japanese workers in the field of information services has been reported (34). This discrepancy may be partly explained by the fact that they selected a different job type, examined young participants (mean 30 years), and measured the brachial-ankle pulse-wave velocity. As for the stiffness parameter, the crude geometric means of stiffness were slightly increased in the high job-strain groups although it did not reach statistical significance in the multivariate-adjusted model, partially due to the large standard deviation of the stiffness value. In other studies, the evaluation of carotid arteriosclerosis used an index of intima-media thickness determined by B-mode ultrasound $(11,35)$. The stiffness parameter, which reflects the elasticity of the vessel (28), may be a weaker index than intima-media thickness, which is a quantitative measure and reflects general arteriosclerosis (36).

The methodological issues should be discussed. First, measurement error should be minimized to avoid getting chance and biasd findings. We set the standardized protocol for each examination item to minimize both the inter- and intraobserver errors. In addition, for MRI, the quality of imaging and film evaluation was controlled. Naturally, all the examinations and evaluations were done under blind conditions in terms of the participants' job-strain scores. Second, confounding factors should be controlled properly if they exist. In the analysis, the major, well-known risk factors were adjusted for, including age, smoking status, alcohol consumption, total cholesterol, systolic blood pressure, hemoglobin $A_{1 c}$, the presence of type-A behavior pattern, body mass index, educational history, and shift work; high job strain still remained a significant, independent risk factor for arteriosclerosis in different types of arteries even though it is always possible that residual confounding or unmeasured confounders may have affected the regression coefficients. It is noteworthy that the proportion of smokers in this study was relatively high (67\%). This figure reflects that of Japanese males 
of working age in general at the time the study was conducted (37). The internal validity of the study seems to have been valid, as has already been discussed, but the generalizability might be considered in a prudent manner. Finally, the issue of temporality should be raised since this was a cross-sectional study (38). A changing pattern of job strain may also be important as job strain was assessed at one time point. Future research with a longitudinal design and repeated measurements of job strain is needed to confirm our results.

In conclusion, the study suggested that high job strain was related to arteriosclerosis in different types of arteries. Our results offer new information on the relationship between job strain and cerebral arteriosclerosis by showing increased numbers of hyperintense spots in T2-weighted images. This finding is especially important in Japan, where the mortality rate for cerebrovascular disease is so high (39). Reducing job strain may contribute to preventing cardiovascular and cerebrovascular disease.

\section{Acknowledgments}

This study was supported by the Japan Chemical Fiber Association.

\section{References}

1. Johnson JV, Hall EM, Theorell T. Combined effects of job strain and social isolation on cardiovascular disease morbidity and mortality in a random sample of the Swedish male working population. Scand J Work Environ Health. 1989;15:271-9.

2. Reed DM, LaCroix AZ, Karasek RA, Miller D, MacLean CA. Occupational strain and the incidence of coronary heart disease. Am J Epidemiol. 1989;129:495-502.

3. Astrand NE, Hanson BS, Isacsson SO. Job demands, job decision latitude, job support, and social network factors as predictors of mortality in a Swedish pulp and paper company. Br J Ind Med. 1989;46:334-40.

4. Hammar N, Alfredsson L, Johnson JV. Job strain, social support at work, and incidence of myocardial infarction. Occup Environ Med. 1998;55:548-53.

5. Uchiyama S, Kurasawa T, Sekizawa T, Nakatsuka H. Job strain and risk of cardiovascular events in treated hypertensive Japanese workers: hypertension follow-up group study. J Occup Health. 2005;47:102-11.

6. Kivimäki M, Virtanen M, Elovainio M, Kouvonen A, Väänänen A, Vahtera J. Work strain in the etiology of coronary heart disease - a meta-analysis. Scand J Work Environ Health. 2006;32(6, special issue):431-42.

7. Theorell T, de Faire U, Johnson J, Hall E, Perski A, Stewart W. Job strain and ambulatory blood pressure profiles. Scand J Work Environ Health. 1991;17:380-5.

8. Landsbergis PA, Schnall PL, Warren K, Pickering TG, Schwartz JE. Association between ambulatory blood pressure and alternative formulations of job strain. Scand J Work Environ Health. 1994;20:349-63.

9. Kawakami N, Haratani T, Araki S. Job strain and arterial blood pressure, serum cholesterol, and smoking as risk factors for coronary heart disease in Japan. Int Arch Occup Environ Health. 1998;71:429-32.

10. Siegrist J, Matschinger H, Cremer P, Seidel D. Atherogenic risk in men suffering from occupational strain. Atherosclerosis. 1988;69:211-8.

11. Muntaner C, Nieto FJ, Cooper L, Meyer J, Szklo M, Tyroler HA. Work organization and atherosclerosis: findings from the ARIC study. Am J Prev Med. 1998;14:9-18.

12. Everson SA, Lynch JW, Chesney MA, Kaplan GA, Goldberg $\mathrm{DE}$, Shade RD, et al. Interaction of workplace demands and cardiovascular reactivity in progression of carotid atherosclerosis: population based study. BMJ. 1997;314:553-8.

13. Karasek R, Baker D, Marxer F, Ahlbom A, Theorell T. Job decision latitude, job demands, and cardiovascular disease: a prospective study of Swedish men. Am J Public Health. 1981;71:694-705.

14. Karasek RA, Theorell T, Schwartz JE, Schnall PL, Pieper CF, Michela JL. Job characteristics in relation to the prevalence of myocardial infarction in the US Health Examination Survey (HES) and the Health and Nutrition Examination Survey (HANES). Am J Public Health. 1988;78:910-8.

15. Kuper H, Adami HO, Theorell T, Weiderpass E. The socioeconomic gradient in the incidence of stroke: a prospective study in middle-aged women in Sweden. Stroke. 2007;38:27-33.

16. Kivimäki M, Leino-Arjas $P$, Luukkonen R, Riihimäki $H$, Vahtera J, Kirjonen J. Work strain and risk of cardiovascular mortality: prospective cohort study of industrial employees. BMJ. 2002;325:857-61.

17. Yanagawa $H$, Nakamura Y, editors. Manual of public health [in Japanese]. Tokyo: Nanzando Company; 2006. p 36.

18. Belkic KL, Landsbergis PA, Schnall PL, Baker D. Is job strain a major source of cardiovascular disease risk? Scand J Work Environ Health. 2004;30(2):85-128.

19. Nishiwaki Y, Takebayashi T, O’Uchi T, Nomiyama T, Uemura T, Sakurai H, et al. Six year observational cohort study of the effect of carbon disulphide on brain MRI in rayon manufacturing workers. Occup Environ Med. 2004;61:225-32.

20. Takebayashi T, Nishiwaki Y, Uemura T, Nakashima H, Nomiyama T, Sakurai H, et al. A six year follow up study of the subclinical effects of carbon disulphide exposure on the cardiovascular system. Occup Environ Med. 2004;61:127-34.

21. Karasek R. Job demands, job decision latitude, and mental strain: implications for job redesign. Admin Sci Q. 1979;24:285-308.

22. Kawakami N, Fujigaki Y. Reliability and validity of the Japanese version of Job Content Questionnaire: replication and extension in computer company employees. Ind Health. 1996;34:295-306.

23. Kawakami N, Kobayashi F, Araki S, Haratani T, Furui H. Assessment of job strain dimensions based on the job demands - control model of employees of telecommunication and electric power companies in Japan: reliability and validity of the Japanese version of the Job Content Questionnaire. Int J Behav Med. 1995;2:358-75.

24. Sawada T, Taneda J, Okamoto K, Okudera T, Kobayashi S, Tougi H, et al. Study on diagnostic criteria for asymptomatic cerebrovascular diseases [in Japanese]. Jpn J Stroke. 1997;19:489-93.

25. Takao M, Koto A, Tanahashi N, Fukuuchi Y, Takagi M, Morinaga S. Pathologic findings of silent, small hyperintense 
foci in the basal ganglia and thalamus on MRI. Neurology. 1999;52:666-8.

26. Takao M, Koto A, Tanahashi N, Fukuuchi Y, Takagi M, Morinaga S. Pathologic findings of silent hyperintese white matter lesions on MRI. J Neurol Sci. 1999;167:127-31.

27. van Popele NM, Grobbee DE, Bots ML, Asmar R, Topouchian J, Reneman RS, et al. Association between arterial stiffness and atherosclerosis The Rotterdam Study. Stroke. 2001;32:45460.

28. Hirai T, Sasayama S, Kawasaki T, Yagi S. Stiffness of systemic arteries in patients with myocardial infarction: a noninvasive method to predict severity of coronary atherosclerosis. Circulation. 1989;80:78-86.

29. Wada T, Kodaira K, Fujishiro K, Maie K, Tsukiyama E, Fukumoto T, et al. Correlation of ultrasound-measured common carotid artery stiffness with pathological findings. Arterioscler Thromb. 1994;14:479-82.

30. Ha M, Park J. Shiftwork and metabolic risk factors of cardiovascular disease. J Occup Health. 2005;47:89-95.

31. Maeda S. Application of a brief questionnaire for the behavior pattern survey [in Japanese]. Type A. 1991;2:33-40.

32. Kobayashi S, Okada K, Koide H, Bokura H, Yamaguchi S. Subcortical silent brain infarction as a risk factor for clinical stroke. Stroke. 1997;28:1932-9.

33. Bernick C, Kuller L, Dulberg C, Longstreth WT, Manolio T, Beauchamp N, et al. Silent MRI infarcts and the risk of future stroke: the cardiovascular health study. Neurology.
2001;57:1222-9.

34. Nomura K, Nakao M, Karita K, Nishikitani M, Yano E. Association between work-related psychological strain and arterial stiffness measured by brachial-ankle pulse-wave velocity in young Japanese males from an information service company. Scand J Work Environ Health. 2005;31:352-9.

35. Hintsanen M, Kivimäki M, Elovainio M, Pulkki-Råback L, Keskivaara P, Juonala M, et al. Job strain and early atherosclerosis: the Cardiovascular Risk in Young Finns study. Psychosom Med. 2005;67:740-7.

36. Grobbee DE, Bots ML. Carotid artery intima-media thickness as an indicator of generalized atherosclerosis. J Intern Med. 1994;236:567-73.

37. Okamura T, Hayakawa T, Kadowaki T, Kita Y, Okayama A, Ueshima H. The inverse relationship between serum highdensity lipoprotein cholesterol level and all-cause mortality in a 9.6-year follow-up study in the Japanese general population. Atherosclerosis. 2006;184:143-50.

38. Härmä M, Kompier MAJ, Vahtera J. Work-related strain and health-risks, mechanisms and countermeasures. Scand J Work Environ Health. 2006;32(6, special issue):413-9.

39. Miwa N, Nakamura T, Naruse Y, Ooe Y, Ohno Y. The effects of various factors on cerebrovascular disease mortality rates in the 20th century and future trends in Japan [in Japanese]. Nippon Koshu Eisei Zasshi. 2006;53:493-503.

Received for publication: 2 March 2006 